\title{
Cancer cell death induced by novel small molecules degrading the TACC3 protein via the ubiquitin- proteasome pathway
}

\author{
N Ohoka ${ }^{1}, \mathrm{~K} \mathrm{Nagai}^{2}$, T Hattori ${ }^{1}, \mathrm{~K}$ Okuhira ${ }^{1}$, N Shibata ${ }^{1}, \mathrm{~N} \mathrm{Cho}^{2}$ and M Naito ${ }^{*, 1}$
}

The selective degradation of target proteins with small molecules is a novel approach to the treatment of various diseases, including cancer. We have developed a protein knockdown system with a series of hybrid small compounds that induce the selective degradation of target proteins via the ubiquitin-proteasome pathway. In this study, we designed and synthesized novel small molecules called SNIPER(TACC3)s, which target the spindle regulatory protein transforming acidic coiled-coil-3 (TACC3). SNIPER(TACC3)s induce poly-ubiquitylation and proteasomal degradation of TACC3 and reduce the TACC3 protein level in cells. Mechanistic analysis indicated that the ubiquitin ligase APC/C ${ }^{\mathrm{CDH} 1}$ mediates the SNIPER(TACC3)-induced degradation of TACC3. Intriguingly, SNIPER(TACC3) selectively induced cell death in cancer cells expressing a larger amount of TACC3 protein than normal cells. These results suggest that protein knockdown of TACC3 by SNIPER(TACC3) is a potential strategy for treating cancers overexpressing the TACC3 protein.

Cell Death and Disease (2014) 5, e1513; doi:10.1038/cddis.2014.471; published online 6 November 2014

Inhibitors of microtubule polymerization or depolymerization such as Vinca alkaloids and taxanes, respectively, are widely used as anti-cancer drugs. They arrest cancer cells, inducing mitotic catastrophe and cancer cell death. However, these drugs also affect microtubule function in non-dividing cells and have serious side effects, such as peripheral neuropathy, which limit their utility. ${ }^{1}$ Recently, inhibitors of spindleregulatory proteins, such as mitotic kinases (Aurora kinases and Polo-like kinases) and a motor protein (Eg5/Ksp) have attracted considerable attention, but they have not been developed clinical use yet. ${ }^{2,3}$

Transforming acidic coiled-coil-3 (TACC3) is another spindle-regulatory protein. $^{4,5}$ During mitosis, TACC3 localizes to the mitotic spindle and has a critical role in spindle assembly, chromosomal function and mitotic progression. ${ }^{6-11}$ Studies using microarray and immunohistochemical analysis showed that TACC3 is overexpressed in many human cancers, including ovarian cancer, breast cancer, squamous cell carcinoma and lymphoma. ${ }^{12-14}$ Depletion of TACC3 results in chromosome alignment defects, multi-polar spindle formation, mitotic cell death and/or a postmitotic cell cycle arrest. ${ }^{15-20}$ Additionally, conditional disruption of TACC3 has been shown to regress thymic lymphomas in p53-deficient mice without inducing any overt abnormalities in normal tissues. $^{21}$ These findings suggest that TACC3 is a molecular target for anti-cancer drug discovery.

The development of a strategy for the selective degradation may be a useful approach to the discovery of novel drugs.
Based on the ubiquitin-proteasome system (UPS), we have devised a protein knockdown system for inducing the selective degradation of target proteins by using specifically designed hybrid small compounds. ${ }^{22-29}$ These compounds, which we have termed SNIPER (Specific and Non-genetic IAPdependent Protein ERaser), are composed of two different ligands connected by a linker; one is a ligand for cellular inhibitor of apoptosis protein 1 (clAP1) and the other a ligand for the target protein. Accordingly, SNIPER is expected to crosslink the ubiquitin-ligase clAP1 and the target protein in the cells, thereby inducing ubiquitylation and, ultimately, proteasomal degradation of the target protein. To date, we have constructed SNIPERs that target cellular retinoic acid binding protein-II (CRABP-II) and nuclear receptors such as estrogen receptor $a(E R a)$ for degradation. ${ }^{22-28}$ In this study, we designed and synthesized novel SNIPERs targeting TACC3, that is, SNIPER(TACC3)s, that induce proteasomal degradation of the TACC3 protein. We also show that cancer cells expressing a large amount of the TACC3 protein readily undergo cell death as the result of SNIPER(TACC3) treatment.

\section{Results}

Effect of SNIPER(TACC3) on TACC3 protein expression. We designed and synthesized the SNIPER(TACC3) to target the TACC3 protein for degradation (Figure 1a). The synthesis and structural data on SNIPER(TACC3)-1 and -2 are presented in Materials and Methods section and Supplementary Information.

${ }^{1}$ Division of Biochemistry and Molecular Biology, National Institute of Health Science, Kamiyoga, Setagaya-ku, Tokyo 158-8501, Japan and ${ }^{2}$ Medicinal Chemistry Research Laboratories, Pharmaceutical Research Division, Takeda Pharmaceutical Co. Ltd., 26-1, Muraoka-Higashi 2-chome, Fujisawa, Kanagawa 251-0012, Japan

${ }^{*}$ Corresponding author: M Naito, Division of Biochemistry and Molecular Biology, National Institute of Health Science, 1-18-1 Kamiyoga, Setagaya-ku, Tokyo 158-8501, Japan. Tel: +81 33700 9428; Fax: +81 33707 6950; E-mail: miki-naito @nihs.go.jp

Abbreviations: TACC3, transforming acidic coiled-coil-3; UPS, ubiquitin-proteasome system; SNIPER, specific and non-genetic IAP-dependent protein eraser; cIAP1, cellular inhibitor of apoptosis protein 1; CRABP-II, cellular retinoic acid binding protein-II; ER $\alpha$, estrogen receptor $\alpha$; Me-BS, methyl-bestatin; PEG, polyethylene glycol; siRNA, small interfering RNA; APC/C, anaphase-promoting complex/cyclosome; 4-OHT, 4-hydroxy tamoxifen; ROS, reactive oxygen species; PI, propidium iodide Received 09.6.14; revised 22.9.14; accepted 24.9.14; Edited by M Agostini 
a

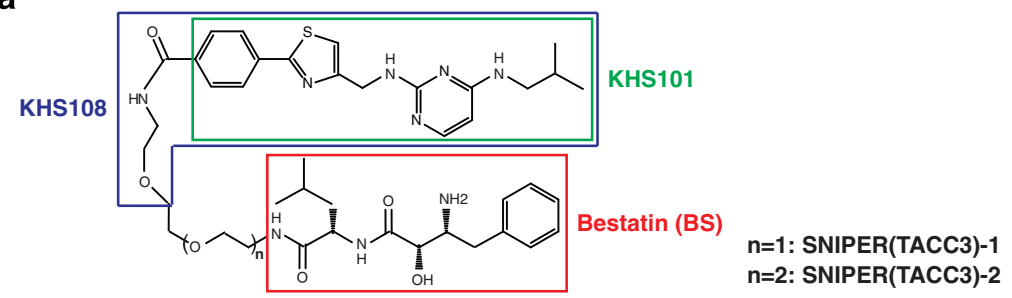

b

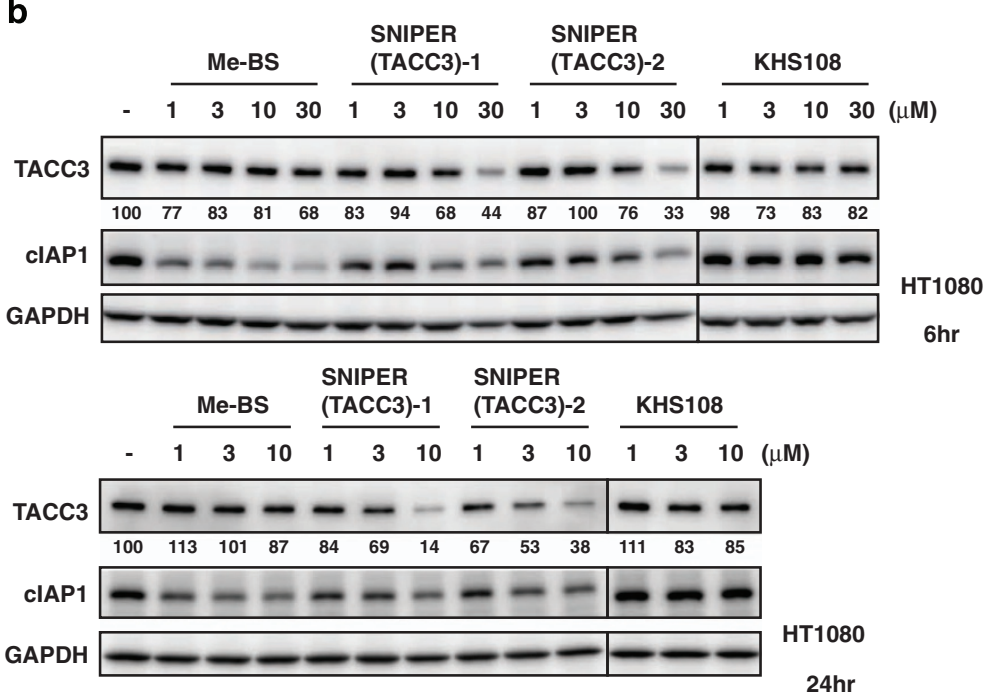

c
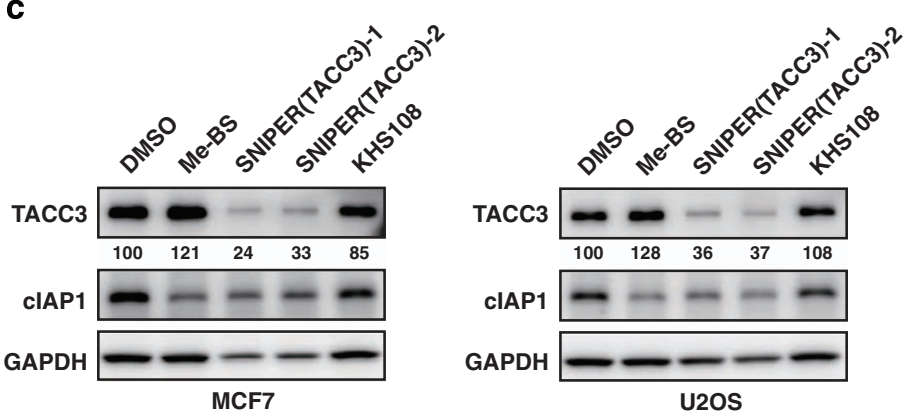

d

e
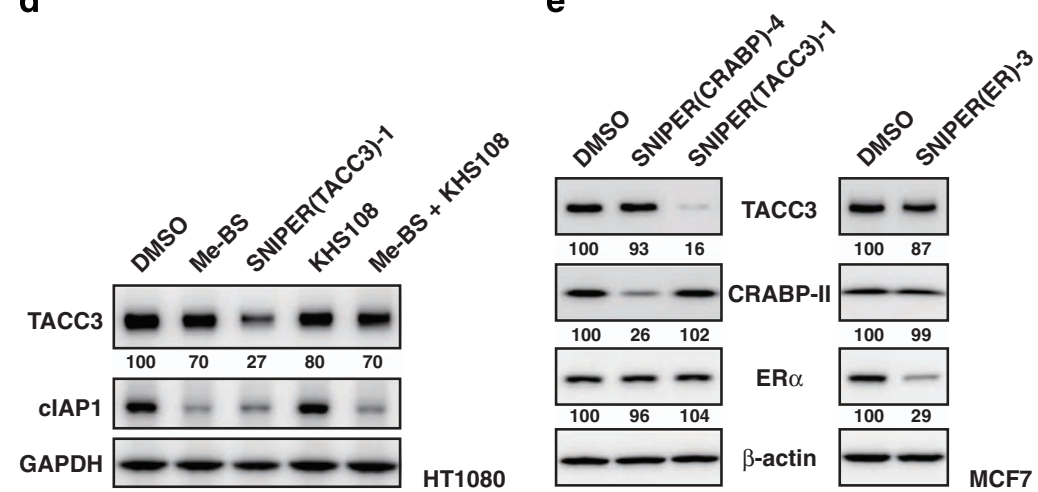

Figure 1 SNIPER(TACC3) decreases the TACC3 protein level. (a) Chemical structure of SNIPER(TACC3). (b) HT1080 cells were treated with the indicated concentration of Me-BS, SNIPER(TACC3)-1, SNIPER(TACC3)-2 or KHS108 for $6 \mathrm{~h}$ (upper panels) or $24 \mathrm{~h}$ (lower panels). (c) MCF7 and U2OS cells were treated with $30 \mu \mathrm{M}$ of Me-BS, SNIPER (TACC3)-1, SNIPER(TACC3)-2 or KHS108 for $6 \mathrm{~h}$. (d) HT1080 cells were treated with $30 \mu \mathrm{M}$ of Me-BS, SNIPER(TACC3)-1, KHS108 or Me-BS plus KHS108 for $6 \mathrm{~h}$. (e) MCF7 cells were treated with $10 \mu \mathrm{M}$ of SNIPER(TACC3)-1 or SNIPER(CRABP)-4 for $6 \mathrm{~h}$ (left panels), or cells precultured in the media containing estrogen-depleted serum were treated with $10 \mu \mathrm{M}$ of SNIPER(ER)-3 for $9 \mathrm{~h}$ (right panels). (b-e) Whole-cell lysates were analyzed using western blotting with the indicated antibodies. The numbers below the protein panels represent the protein level relative to control (dimethyl sulfoxide (DMSO)), which was normalized by glyceraldehyde 3-phosphate dehydrogenase (GAPDH) or $\beta$-actin 
When human fibrosarcoma HT1080 cells were treated with graded concentrations of SNIPER(TACC3)-1 or -2 , the TACC3 level was significantly decreased by these compounds at $30 \mu \mathrm{M}$ for $6 \mathrm{~h}$ and at $10 \mu \mathrm{M}$ for $24 \mathrm{~h}$ (Figure 1b). However, methyl-bestatin (Me-BS) or KHS108 marginally reduced the TACC3 protein level under the same condition. SNIPER(TACC3)s also decreased the clAP1 level, although the effect was less than Me-BS, suggesting that the SNIPER(TACC3)s simultaneously induces auto-ubiquitylation and proteasomal degradation of ClAP1, as observed with other SNIPERs. ${ }^{22,28}$ Similar results were obtained in human breast adenocarcinoma MCF7 or human osteosarcoma U2OS cells when the cells were treated with $30 \mu \mathrm{M}$ of SNIPER(TACC3)s for $6 \mathrm{~h}$ (Figure 1c). Combination treatment with Me-BS and KHS108 did not decrease the TACC3 protein level, indicating that linking the two ligands into a single molecule is critically important for the reduction of the TACC3 protein (Figure 1d). Additionally, we examined the target specificity of the SNIPERs we have developed. SNIPER(TACC3), SNIPER(CRABP) and SNIPER(ER) reduced the level of respective target proteins without reducing the other proteins (Figure 1e), indicating the specificity of SNIPERs on the degradation of the target proteins.

Ubiquitylation and proteasomal degradation of TACC3 protein by SNIPER(TACC3). To investigate whether the reduction of the TACC3 protein by SNIPER(TACC3) is mediated by proteasomal degradation, HT1080 cells were co-treated with SNIPER(TACC3) and the proteasome inhibitor MG132. As shown in Figure 2a, the decrease in the TACC3 protein by SNIPER(TACC3)s was abrogated by MG132, indicating that SNIPER(TACC3)s reduce TACC3 protein by a proteasome-dependent mechanism.

We next examined the effect of SNIPER(TACC3) on the ubiquitylation of TACC3. HT1080 cells were transiently cotransfected with the expression vectors of Flag-tagged TACC3 and HA-tagged ubiquitin and then treated with SNIPER (TACC3)-1 or control compounds in the presence of MG132. The cell lysates were heat-denatured to dissociate non-covalently bound proteins, then re-natured and immunoprecipitated with anti-FLAG (TACC3) antibody. The immunoprecipitates were subsequently analyzed by western blotting with an anti-HA (ubiquitin) to detect ubiquitylated TACC3 proteins (Figure 2b, left panels). SNIPER(TACC3)-1 treatment, but not Me-BS or KHS108, shifted the smear bands of the poly-ubiquitylated TACC3 protein to a more slowly migrating position (near the top of gel), indicating that SNIPER(TACC3) induces a higher level of poly-ubiquitylation of the TACC3 protein. We carried out a similar experiment with an antibody specific to K48-linked ubiquitin and observed a more conspicuous enhancement of K48-polyubiquitylated TACC3 protein by SNIPER(TACC3), but not by Me-BS nor KHS108 (Figure 2b, right panels). These results indicate that SNIPER(TACC3)s induce poly-ubiquitylation and proteasomal degradation of TACC3 proteins within cells.

SNIPER(TACC3)-induced degradation of TACC3 protein requires $A P C / C^{C D H 1}$. As SNIPER(TACC3) is designed to crosslink the ubiquitin ligase CIAP1 to the TACC3 protein, we reasoned that the TACC3 protein is degraded subsequent to CIAP1-mediated ubiquitylation. To examine whether cIAP1 is actually involved in the SNIPER (TACC3)-induced TACC3 degradation, we pretreated the cells with small interfering RNA (siRNA) against clAP1 and measured the reduction of TACC3 protein by SNIPER(TACC3)s. We used three different siRNAs against CIAP1, and they all efficiently downregulated the cIAP1 protein level. Unexpectedly, however, the downregulation of the clAP1 protein did not abrogate the reduction in the TACC3 protein by SNIPER(TACC3)s (Figure 3a). This result suggests that the TACC3 protein is ubiquitylated by a different ubiquitin ligase than CIAP1 in the SNIPER(TACC3)-treated cells.

As an inherent component in the degradation machinery, the anaphase-promoting complex/cyclosome in complex with $\mathrm{CDH} 1$ (APC/ $\mathrm{C}^{\mathrm{CDH} 1}$ ) has been shown to ubiquitylate TACC3 proteins during late mitosis. ${ }^{30}$ To examine whether $\mathrm{APC} / \mathrm{C}^{\mathrm{CDH} 1}$ participates in the SNIPER(TACC3)-dependent degradation of the TACC3 protein, we downregulated key components of $\mathrm{APC} / \mathrm{C}^{\mathrm{CDH} 1}$ by the siRNAs. Knockdown of $\mathrm{CDH} 1$, a substraterecognition subunit for TACC3, completely abolished the reduction of TACC3 protein by SNIPER(TACC3)-1 treatment, while the knockdown of CDC20, another substrate-recognition subunit in APC/C for different proteins, ${ }^{31}$ scarcely attenuated the TACC3 reduction (Figure $3 b$ ). In addition, knockdown of APC11, a RING H2 subunit recruiting E2 enzyme, ${ }^{31}$ and APC3, a core component of $\mathrm{APC} / \mathrm{C}$, also abrogated the TACC3 reduction by SNIPER(TACC3). We repeated the experiments with three different siRNAs against $\mathrm{CDH} 1$, and the abrogation of TACC3 protein knockdown was confirmed (Figure $3 \mathrm{c}$ ). These results indicate that $\mathrm{APC} / \mathrm{C}^{\mathrm{CDH} 1}$ is required for the SNIPER(TACC3)-induced degradation of the TACC3 protein.

To confirm the physical interaction of SNIPER(TACC3) and $\mathrm{APC} / \mathrm{C}^{\mathrm{CDH} 1}$, we performed a thermal shift assay that is based on the biophysical principle of ligand-induced change of thermal sensitivity of target proteins ${ }^{32}$ (Figure 4a). Multiple aliquots of the cell lysates were mixed with each compounds (SNIPER (TACC3)-1, Me-BS or KHS108) and heated to graded temperatures. After cooling, the lysates were centrifuged to precipitate unfolded proteins, and the supernatants were analyzed by western blotting. The thermal sensitivity of APC/ $\mathrm{C}^{\mathrm{CDH} 1}$ components (APC3, APC11 and $\mathrm{CDH} 1$ ) were changed by addition of SNIPER(TACC3)-1, but not by Me-BS and KHS108. On the other hand, the thermal sensitivity of CDC20 was not affected by these compounds. These results indicate the physical interaction of SNIPER(TACC3) and APC/C ${ }^{\mathrm{CDH} 1}$.

Next we examined whether SNIPER(TACC3) treatment increases the interaction between TACC3 and APC/C ${ }^{\mathrm{CDH} 1}$ by crosslinking these proteins. As TACC3 inherently interacts with $\mathrm{APC} / \mathrm{C}^{\mathrm{CDH} 1}$, we tried to discriminate the SNIPER (TACC3)-mediated interaction of these proteins by the following procedure (Figure 4b). HT1080 cells were transiently co-transfected with the expression vectors of Flag-TACC3 and Myc-CDH1 and then treated with MG132 in the presence or absence of SNIPER(TACC3)-1. The cell lysates were immunoprecipitated with anti-FLAG (TACC3) antibody, and the immunoprecipitates were eluted with an excess amount of either $\mathrm{KHS} 108$ or Me-BS to detect the APC/C ${ }^{\mathrm{CDH} 1}$ components that had associated with TACC3 depending on SNIPER(TACC3) (Supplementary Figure S1). Figure 4c shows a significant increase of Myc-CDH1 and endogenous APC3 in the fractions eluted with KHS108 and Me-BS but not with 4-hydroxy tamoxifen (4-OHT) as a control compound. Me-BS eluted the proteins probably by disturbing the binding of SNIPER(TACC3) to $A P C / C^{C D H 1}$. These results strongly suggest that there are 
a

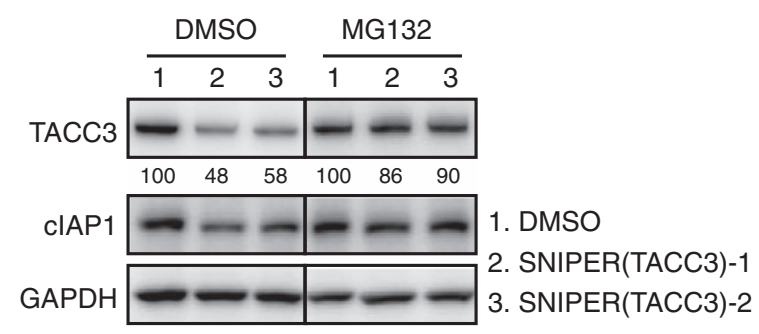

b

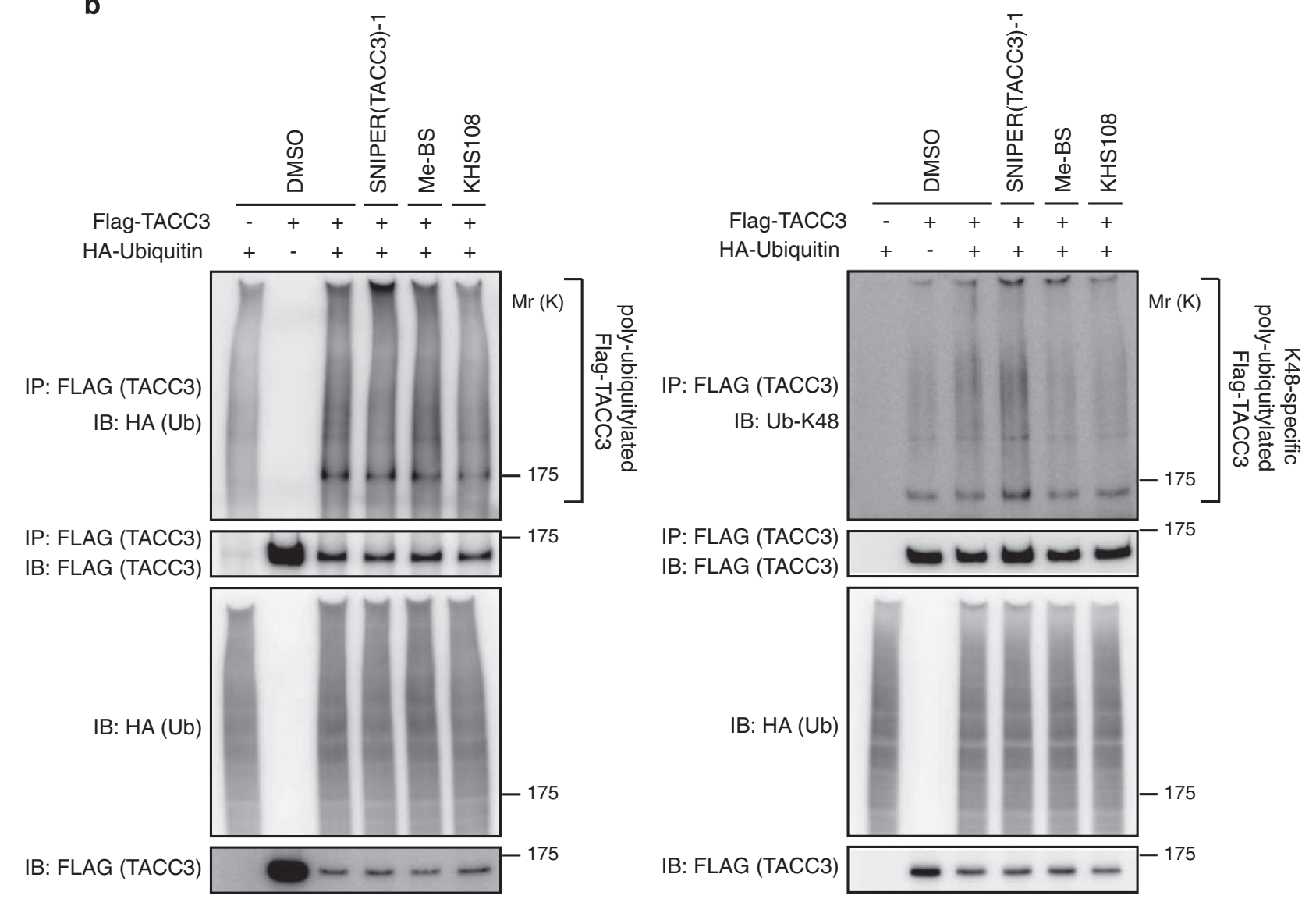

Figure 2 SNIPER(TACC3) induces ubiquitylation and proteasomal degradation of TACC3. (a) HT1080 cells were treated with $30 \mu \mathrm{M}$ of SNIPER(TACC3)-1 or -2 in the presence or absence of $25 \mu \mathrm{M}$ of MG132 for $4 \mathrm{~h}$. Whole-cell lysates were analyzed using western blotting with the indicated antibodies. The numbers below the TACC3 panels represent the TACC3 level relative to the respective control normalized by glyceraldehyde 3-phosphate dehydrogenase (GAPDH). (b) HT1080 cells were co-transfected with the expression vector of Flag-TACC3 and/or HA-ubiquitin. After $40 \mathrm{~h}$, cells were treated with the indicated compounds in the presence of $25 \mu \mathrm{M}$ of MG132 for $3 \mathrm{~h}$. Cells were lysed, and Flag-TACC3 was immunoprecipitated with an anti-FLAG antibody. The ubiquitylated TACC3 was detected with an anti-HA antibody (left panels) or an antibody specific to K48linked ubiquitin (right panels). DMSO, dimethyl sulfoxide; IB, immunoblot; IP, immunoprecipitation

two types of interaction between TACC3 and APC/C $\mathrm{C}^{\mathrm{CDH} 1}$ : one is an inherent interaction independent of SNIPER(TACC3) (Supplementary Figure S1A), and the other is a SNIPER (TACC3)-mediated interaction (Supplementary Figure S1B). SNIPER(TACC3) is likely to increase the amount of TACC3 associated with $A P C / C^{\mathrm{CDH} 1}$ via the second mechanism.

As the SNIPER(TACC3) interacts with $A P C / C^{C D H 1}$, it is possible that it directly activates $\mathrm{APC} / \mathrm{C}^{\mathrm{CDH} 1}$ and promotes the degradation of many target proteins. Therefore, we explored the possibility that SNIPER(TACC3) may facilitate the degradation of a variety of proteins ubiquitylated by $\mathrm{APC} / \mathrm{C}^{\mathrm{CDH} 1}$. As cyclin B and CDC20 are known to be ubiquitylated by $\mathrm{APC} / \mathrm{C}^{\mathrm{CDH} 1},{ }^{33}$ the turnover of these proteins was examined after
SNIPER(TACC3) treatment. The result showed that TACC3 was scarcely degraded until $6 \mathrm{~h}$ in control cells, but rapidly degraded in the SNIPER(TACC3)-treated cells, with a half-life of approximately $5 \mathrm{~h}$ (Figure 5). However, the degradation of cyclin $\mathrm{B}$ and CDC20 was unaffected by SNIPER(TACC3)-1 treatment. This result suggests that SNIPER(TACC3) specifically facilitates degradation of the TACC3 protein. We also investigated cell cycle distribution of HT1080 cells treated with SNIPER(TACC3)1 for $4 \mathrm{~h}$ (Supplementary Figure S2). The result showed that SNIPER(TACC3) did not affect the cell cycle distribution, suggesting that the degradation of TACC3 by SNIPER (TACC3)- 1 is not due to arresting cells in a certain cell cycle phase where the protein is preferentially degraded. 


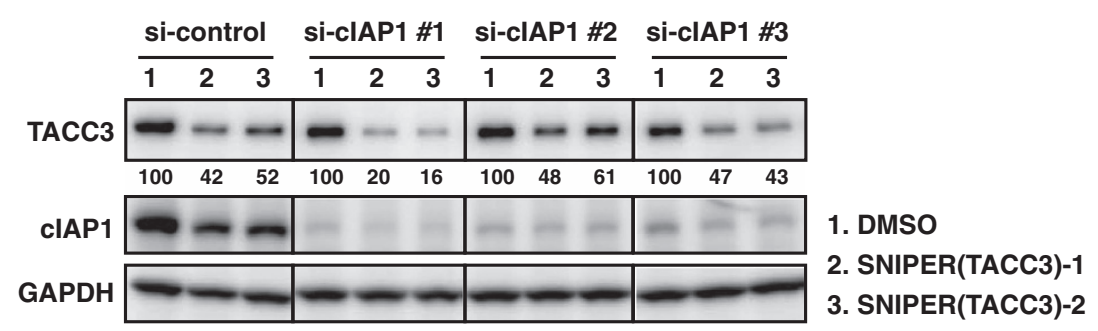

b

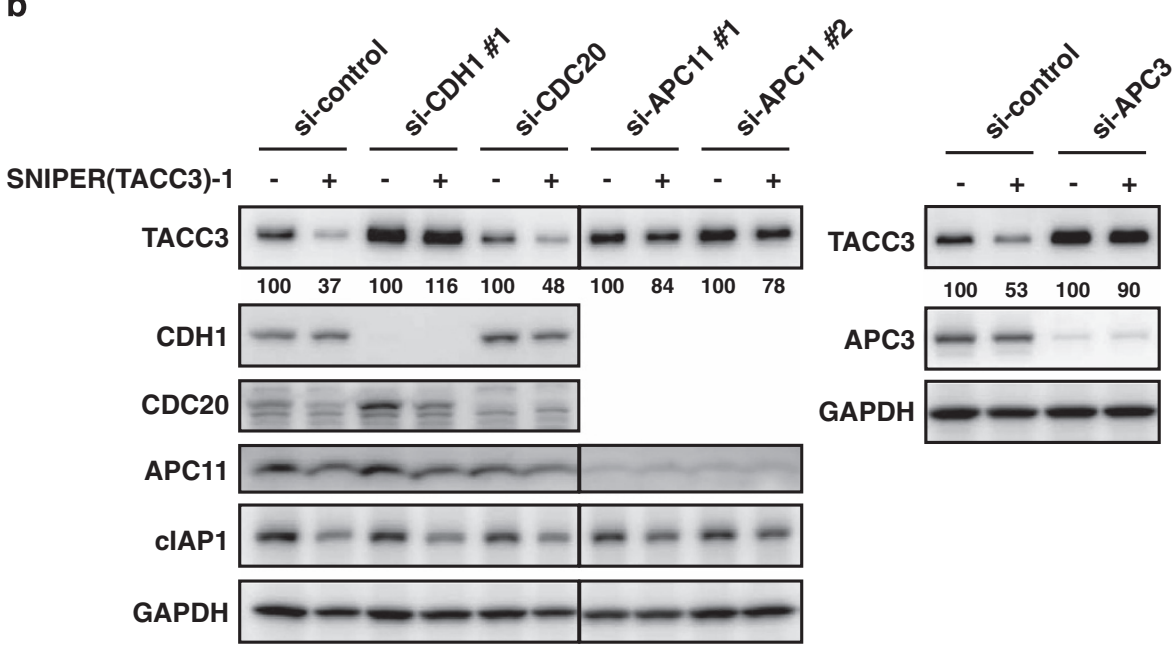

C

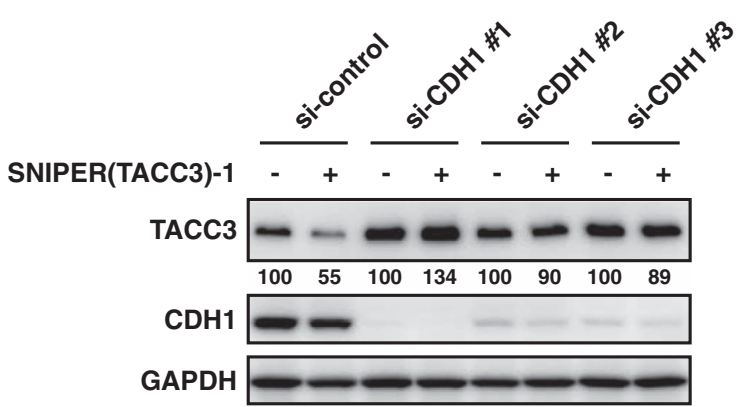

Figure $3 \mathrm{APC} / \mathrm{C}^{\mathrm{CDH} 1}$ mediates SNIPER-induced TACC3 reduction. (a-c) HT1080 cells were transfected with the indicated siRNA for $40 \mathrm{~h}$ and treated with $30 \mu \mathrm{M}$ of SNIPER (TACC3)-1 for $4 \mathrm{~h}$. Whole-cell lysates were analyzed using western blotting with the indicated antibodies. The numbers below the TACC3 panels represent the TACC3 level relative to the respective control normalized by glyceraldehyde 3-phosphate dehydrogenase (GAPDH). DMSO, dimethyl sulfoxide

Selective cytotoxicity of SNIPER(TACC3) against cancer cells. In some cancer cell lines, depletion of TACC3 induces postmitotic cell cycle arrest or mitotic cell death. ${ }^{15-19}$ TACC3 deletion was also shown to result in a massive apoptotic regression of mouse thymic lymphoma in vivo without any overt abnormalities in normal tissues. ${ }^{21}$ Therefore, we tested the effect of SNIPER(TACC3) on the cell viability of cancer cells. HT1080 and MCF7 cells were treated with Me-BS, KHS108, their combination or SNIPER (TACC3)-1 for $48 \mathrm{~h}$, and cell viability was determined. SNIPER (TACC3) at $\geq 10 \mu \mathrm{M}$ efficiently killed the cancer cells (Figure 6a), which is consistent with the protein knockdown activity under longterm $(24 \mathrm{~h}$ ) treatment (Figure $1 \mathrm{~b})$. On the other hand, individual or combined treatment with Me-BS and KHS108 exhibited mild effects on the cell viability up to $30 \mu \mathrm{M}$. In line with this, SNIPER(TACC3)-1 at $10 \mu \mathrm{M}$, but not Me-BS, KHS108 or their combination, induced caspase-3 activation and PARP cleavage in the cells, suggesting SNIPER(TACC3) induces apoptotic cell death (Figure 6b). We also examined the effects of SNIPER(TACC3) on the viability of other cancer cell lines and normal cells. Figure $6 \mathrm{c}$ shows that the cell viability was greatly reduced by SNIPER(TACC3)-1 and -2 in human cancer cells but minimally in normal human fibroblasts. Selective induction of apoptosis in cancer cells by SNIPER(TACC3) was confirmed by Annexin V/propidium iodide (PI) staining (Supplementary Figure S3) and flow cytometric analysis (Supplementary Figure S4). To understand the mechanism behind the selective toxicity of SNIPER(TACC3) against cancer cells, we compared the level of TACC3 protein. Figure $6 \mathrm{~d}$ shows that the expression level of TACC3 protein in cancer cells was much higher than that in normal cells. Depletion of TACC3 by siRNA showed only mild effect on cell cycle distribution and cell viability in these cell lines (Supplementary Figure S5). However, when SNIPER (TACC3)-induced degradation of TACC3 protein was abrogated by siRNA against $\mathrm{APC} / \mathrm{C}^{\mathrm{CDH} 1}$ components (Figures $3 \mathrm{~b}$ and $\mathrm{c}$ ), SNIPER(TACC3)-induced cancer cell death was seriously 
a

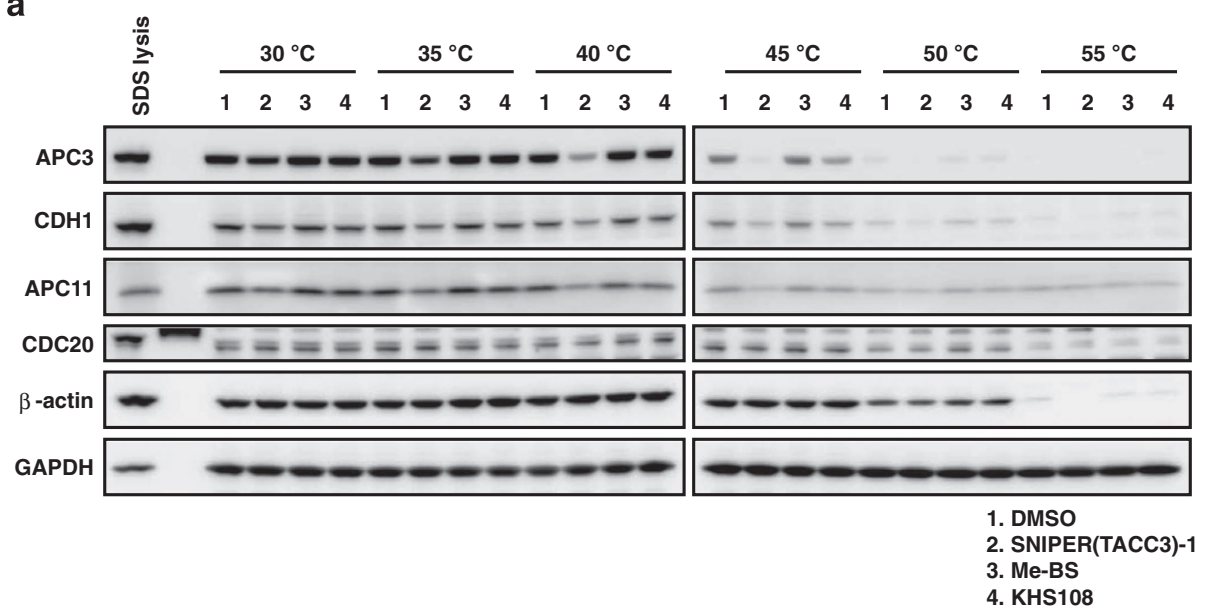

b

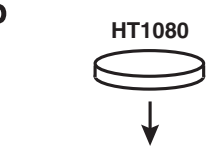

Transfection of Flag-TACC3 and Myc-CDH1
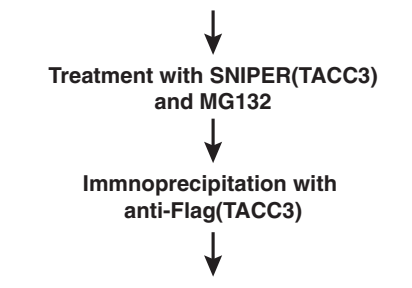

Elution with KHS108, Me-BS or 4-OHT
C

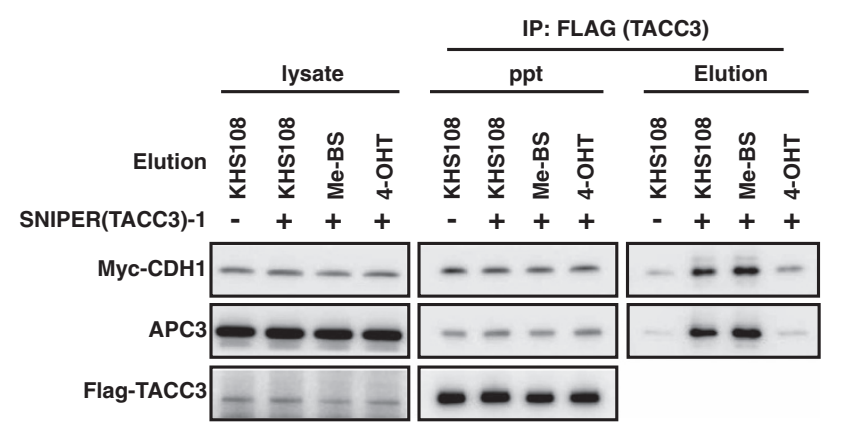

SDS-PAGE and Immunoblot

Figure 4 SNIPER(TACC3) physically interacts with $\mathrm{APC} / \mathrm{C}^{\mathrm{CDH} 1}$ and increases the $\mathrm{TACC} 3-\mathrm{APC} / \mathrm{C}^{\mathrm{CDH} 1}$ interaction. (a) Cell lysates were mixed with $100 \mu \mathrm{M}$ of $\mathrm{SNIPER}$ (TACC3)-1, Me-BS or KHS108 and analyzed by a thermal shift assay. (b) Scheme of the experimental procedure to detect the SNIPER(TACC3)-mediated interaction of TACC3 and $A P C / C^{C D H 1}$. (c) HT1080 cells were co-transfected with the expression vector of Flag-TACC3 and Myc-CDH1. After $40 \mathrm{~h}$, cells were treated with $25 \mu \mathrm{M}$ of MG132 in the presence or absence of $30 \mu \mathrm{M}$ of SNIPER(TACC3)-1 for $3 \mathrm{~h}$. Cells were lysed in immunoprecipitated (IP) lysis buffer and Flag-TACC3 was IP with an anti-FLAG antibody. The precipitates were eluted with $2 \mathrm{mM}$ of KHS108, Me-BS or 4-OHT. Total cell lysates, immunoprecipitates after elution and eluted fractions were western blotted with the indicated antibodies. DMSO, dimethyl sulfoxide; Elution, eluted fraction; lysate, total lysate; ppt, immunoprecipitate after elution; SDS-PAGE, sodium dodecyl sulfate-polyacrylamide gel electrophoresis

suppressed (Supplementary Figure S6). These results suggest that SNIPER(TACC3) selectively kills cancer cells expressing a large amount of the TACC3 protein, and the degradation of TACC3 protein has an important role in the SNIPER(TACC3)-induced cancer cell death.

\section{Discussion}

Protein knockdown with SNIPER technology selectively degrades target proteins by small molecules composed of two ligands, one against CIAP1 and the other against a target protein. Theoretically, this method enables the induction of a rapid degradation of a target even if it is a long-lived protein, which stands in contrast with the repression of protein synthesis by SiRNA and antisense oligonucleotides that require a longer time to achieve efficient knockdown. We have developed a series of SNIPER compounds targeting a variety of proteins, including CRABP-II and ER $a^{22-28}$ These SNIPERs are designed to induce clAP1-mediated ubiquitylation and proteasomal degradation of the target proteins, and they actually reduce the target proteins by the expected mechanism.

In this study, on the basis of our previous success, we designed and synthesized SNIPER(TACC3) to target TACC3 protein for degradation. The SNIPER(TACC3) induces proteasomal degradation of the TACC3 protein in the cells, as intended. Unexpectedly, however, clAP1 is not involved in the SNIPER(TACC3)-mediated protein knockdown of the TACC3 protein. Instead, $\mathrm{APC} / \mathrm{C}^{\mathrm{CDH} 1}$ has an important role in the degradation of the TACC3 induced by SINPER(TACC3). As $A P C / C^{C D H 1}$ is a physiological E3 ligase for $\mathrm{TACC}^{30}$ and SNIPER(TACC3) interacts with APC/C ${ }^{\mathrm{CDH} 1}$, it is possible that SNIPER(TACC3) non-specifically activates APC/C ${ }^{\mathrm{CDH} 1}$ in order to facilitate the ubiquitylation and degradation of many different proteins. However, this is not the case, because degradation of cyclin B and CDC20, both of which are substrates for $A P C / C^{C D H 1}$-mediated ubiquitylation as well, were not facilitated by SNIPER(TACC3). A thermal shift assay 


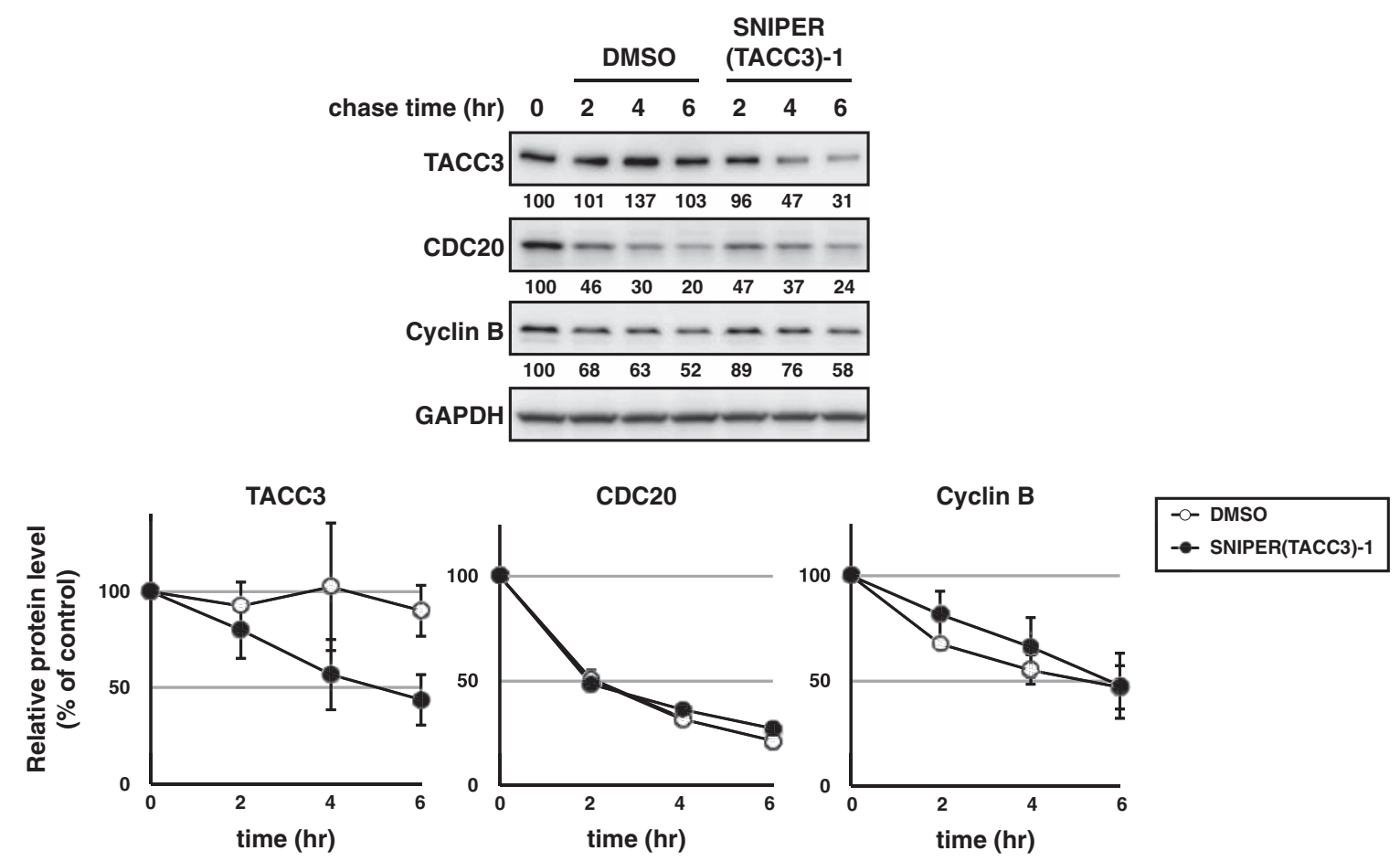

Figure 5 Turnover rate of APC/C substrate proteins. HT1080 cells were treated with $10 \mu \mathrm{g} / \mathrm{ml}$ of cycloheximide in the presence or absence of $30 \mu \mathrm{M}$ of SNIPER(TACC3)- 1 for the indicated periods. Whole-cell lysates were analyzed using western blotting with the indicated antibodies (top). The expression levels of TACC3, CDC20 and Cyclin B were normalized by glyceraldehyde 3-phosphate dehydrogenase (GAPDH), and the relative levels compared with time 0 were evaluated. The graphs are the means \pm S.D. of a representative experiment performed in triplicate (bottom). DMSO, dimethyl sulfoxide

and co-immunoprecipitation followed by elution with individual ligands (KHS108 and Me-BS) (Figure 4) suggest that SNIPER (TACC3) crosslinks TACC3 and APC/C ${ }^{\mathrm{CDH} 1}$, thereby increasing the interaction of these proteins (Supplementary Figure S1). Thus, unlike other SNIPERs that induce cIAP1-mediated ubiquitylation of target proteins, SNIPER(TACC3) induces APC/C $\mathrm{C}^{\mathrm{CDH} 1}$-mediated ubiquitylation of the TACC3 protein. In all cases, the ubiquitylated proteins were subjected to proteasomal degradation, resulting in a reduction of the target.

TACC3 has a pivotal role on the regulation of spindle formation. When the TACC3 protein is depleted by siRNA or genetic ablation, cell lines show mitotic or postmitotic arrest and occasionally undergo apoptosis..$^{7,15,16,19,20}$ However, as thus far examined with SNIPER(TACC3)s, we did not observe any mitotic arrest but rather cell death via apoptosis. This may be due to an insufficient reduction of the TACC3 protein and/or simultaneous reduction of anti-apoptotic clAP1 protein by SNIPER(TACC3) treatment. It is also possible that SNIPER (TACC3) additionally affect a cellular function related to cell death. In the case of SNIPER(ER), there is a robust production of reactive oxygen species (ROS) after ERa degradation that results in necrotic cell death accompanied by the release of HMGB1 from the cells. ${ }^{28}$ SNIPER(TACC3), however, does not induce a robust $\mathrm{ROS}$ production in cells.

One of the interesting feature of SNIPER(TACC3) is the ability to induce apoptosis selectively in cancer cells expressing large amounts of TACC3 protein. As TACC3 level is higher in actively dividing cells, SNIPER(TACC3) might selectively kill cancer cells that are more actively proliferating than non-tumor cells. Degradation of TACC3 seems to have an important role in the SNIPER(TACC3)-induced apoptosis, because downregulation of $\mathrm{APC} / \mathrm{C}^{\mathrm{CDH} 1}$-components by siRNA abrogates the SNIPER(TACC3)-induced TACC3 degradation (Figure 3), and suppresses cell death (Supplementary Figure S6), though TACC3 depletion by siRNA is not enough to induce cell death in these cancer cells (Supplementary Figure S5),

Recently, TACC3 has attracted increasing attention as a target for cancer therapy, ${ }^{21,34-41}$ and inhibitors of TACC3 have been reported to possess anti-tumor activity. ${ }^{42}$ As SNIPER (TACC3) exhibits selective toxicity to cancer cells aberrantly expressing large amount of the TACC3 protein as compared with normal cells, protein knockdown is a strategy for disrupting TACC3 function in cancer cells.

\section{Materials and Methods}

Design and synthesis of SNIPER(TACC3)-1 and -2. The smallmolecule KHS101 and its derivative KHS108 have been reported to interact with the TACC3 protein. ${ }^{43}$ Accordingly, KHS101 and bestatin were used as TACC3 and CIAP1 ligands, respectively. We designed the hybrid molecules SNIPER(TACC3)-1 and -2 in which KHS108 is linked to bestatin via a linker having a different polyethylene glycol (PEG) unit (Figure 1a). The attachment point of KHS108 to the PEG linker was determined at the end of the methoxyethylaminocarbonyl group, which does not affect the neuronal differentiation activities of KHS101 derivatives according to the literature. ${ }^{43}$

The chemical synthesis and physicochemical data on SNIPER(TACC3)-1 and -2 are provided in the Supplementary Information.

Plasmids. The CDNA encoding human TACC3 was amplified by PCR from HepG2 cDNA and cloned into a pCMV5-FLAG expression vector. The correct cDNA sequence was confirmed. pcDNA3-Myc-CDH1 was described previously. ${ }^{44}$ 
a

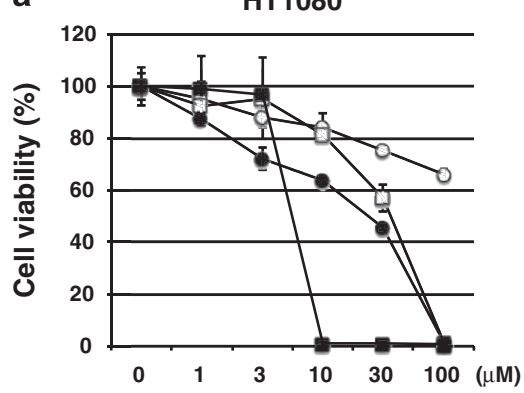

MCF7

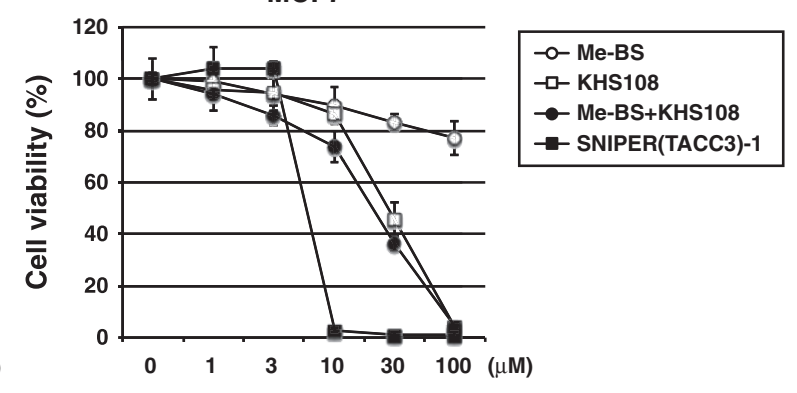

b

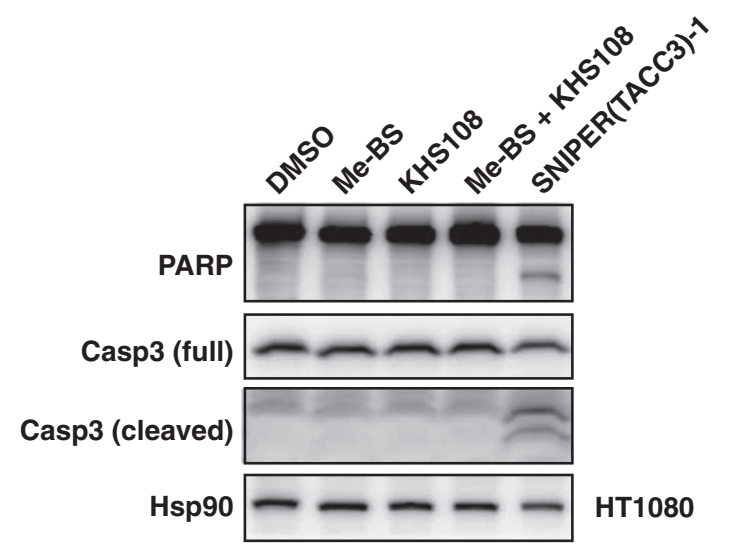

c

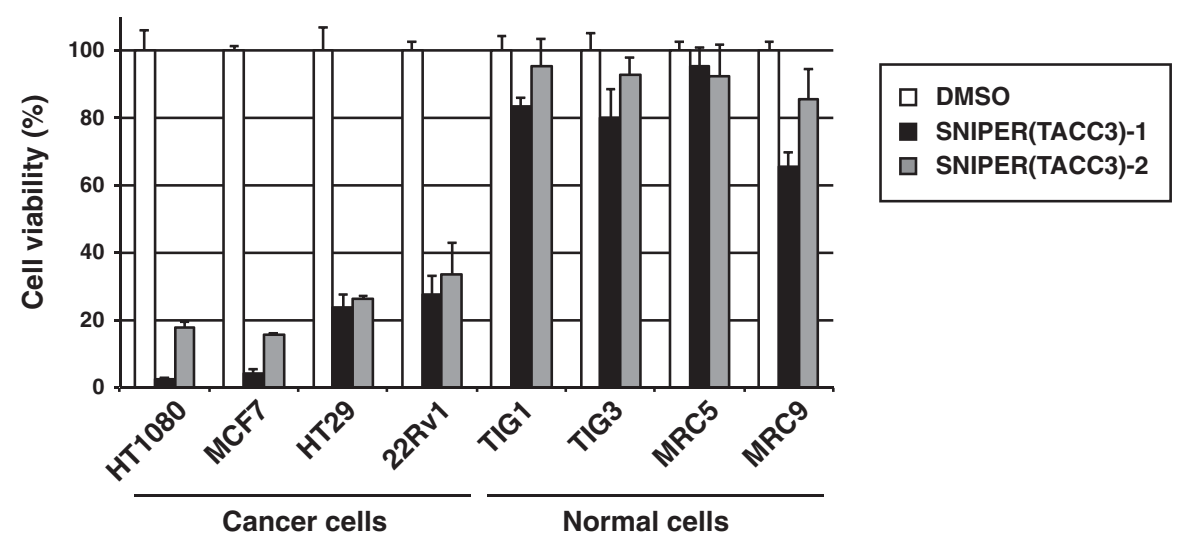

d

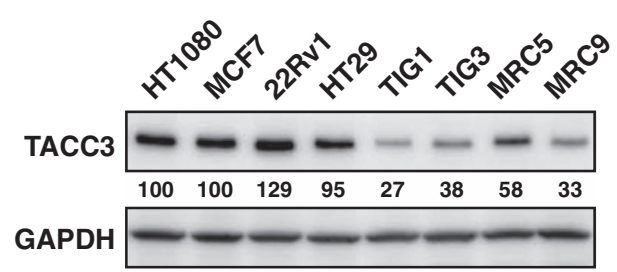

Figure 6 SNIPER(TACC3) selectively induces cancer cell death expressing a large amount of the TACC3 protein. (a and c) Cells were treated with the indicated compounds for $48 \mathrm{~h}$, and cell viability was measured by WST-8 cell proliferation assay. The graphs show the means \pm S.D. of a representative experiment performed in triplicate. (b) Cells were treated with $10 \mu \mathrm{M}$ of the indicated compounds for $24 \mathrm{~h}$, and the whole-cell lysates were analyzed by western blotting with the indicated antibodies. (d) Whole-cell lysates from exponentially growing cells were analyzed by western blotting. The numbers below the TACC3 panel show the relative level of TACC3 compared with HT1080 cells normalized by glyceraldehyde 3-phosphate dehydrogenase (GAPDH). DMSO, dimethyl sulfoxide

Cell culture and transfection. Human fibrosarcoma HT1080, human osteosarcoma U2OS, human colon adenocarcinoma HT29 and human fetal lung fibroblasts TIG1, TIG3, MRC5 and MRC9 were maintained in Dulbecco's modified Eagle's medium supplemented with $10 \%$ fetal bovine serum (FBS) and $100 \mu \mathrm{g} / \mathrm{ml}$ of kanamycin. In some experiments, MCF7 cells were precultured in the media containing estrogen-depleted serum as previously described. ${ }^{28}$ Human breast adenocarcinoma MCF7 and human prostate carcinoma 22Rv1 were maintained in RPMl 1640 medium containing $10 \%$ FBS and $100 \mu \mathrm{g} / \mathrm{ml}$ of kanamycin. HT1080 cells were transiently transfected with gene-specific short interfering RNA (siRNA) or negative control siRNA (QIAGEN, Valencia, CA, USA) using lipofectamine RNAi MAX reagent (Invitrogen, Tokyo, Japan). The siRNA sequences used in this study were: human CIAP1-1 (5'-UCUAGAGCAGUUGAAGACAUCUCUU-3'); CIAP1-2 
(5'-GCUGUAGCUUUAUUCAGAAUCUGGU-3'); CIAP1-3 (5'-GGAAAUGCUGCGG CCAACAUCUUCA-3'); CDH1-1 (5'-GGAUUAACGAGAAUGAGAA-3'); CDH1-2 (5'-UGAGAAGUCUCCCAGUCAG-3'); CDH1-3 (5'-GCACGGAGACCGCUUCAUC-3'); CDC20 (5'-GUCCCCCCGGAAACCCACC-3'); APC11-1 (5'-GGUGAAGAUUAAGU GCUGG-3'); APC11-2 (5'-CGAUGAGAACUGUGGCAUC-3'); and APC3 (5'-GGAA AUAGCCGAGAGGUAA-3').

Western blotting. Cells were lysed with SDS lysis buffer $(0.1 \mathrm{M}$ Tris- $\mathrm{HCl}$ at $\mathrm{pH}$ $8.0,10 \%$ glycerol, $1 \%$ SDS) and boiled for $10 \mathrm{~min}$. The protein concentration was measured by the BCA method (Pierce, Rockford, IL, USA), and the lysates containing an equal amount of protein were separated by SDS-PAGE, transferred to PVDF membranes (Millipore, Darmstadt, Germany) for western blotting using the appropriate antibodies. The immunoreactive proteins were visualized using the Immobilon Western chemiluminescent HRP substrate (Millipore), and light emission was quantified with a LAS-3000 lumino-image analyzer (Fuji, Tokyo, Japan). The antibodies used in this study were: anti-TACC3 rabbit monoclonal antibody (mAb) (Cell Signaling Technology, Danvers, MA, USA; 8069), anti-TACC3 rabbit polyclonal antibody (pAb) (Santa Cruz, Dallas, TX, USA; sc-22773), anti-cIAP1 goat pAb (R\&D systems, Minneapolis, MN, USA; AF8181), anti-GAPDH pAb (Santa Cruz, sc-25778 HRP), anti-CDH1 mouse mAb (Calbiochem, La Jolla, CA, USA; Ab-2), anti-CDC20 rabbit pAb (Santa Cruz, sc-8358), anti-APC11 rabbit pAb (Acris, San Diego, CA, USA; R1503), anti-APC3 mouse mAb (Santa Cruz, sc-13154), anti-cyclin B (Santa Cruz, sc-245), anti-PARP rabbit mAb (Cell Signaling Technology, 9532), anti-caspase-3 rabbit pAb (Santa Cruz, sc-7148) and anti-Hsp90 mouse mAb (BD Transduction, San Jose, CA, USA; 610419), anti-CRABP-\| rabbit pAb (Abcam, Cambridge, UK; ab72099), anti-ER $\alpha$ rabbit mAb (Cell Signaling Technology, 8644), and anti- $\beta$-actin mouse mAb (Sigma, St. Louis, MO, USA; A2228).

Ubiquitylation assay. HT1080 cells were transfected with pCMV5-FLAGTACC3 and pcDNA3-HA-ubiquitin for $40 \mathrm{~h}$ The cells were then incubated with the indicated compounds in the presence of MG132 $(25 \mu \mathrm{M})$ for $3 \mathrm{~h}$ before being harvested and lysed in SDS lysis buffer. The cell lysates were boiled for $10 \mathrm{~min}$ diluted 10 times with IP lysis buffer ( $10 \mathrm{mM}$ Hepes at pH7.4, $142.5 \mathrm{mM} \mathrm{KCl}, 5 \mathrm{mM}$ $\mathrm{MgCl}_{2}, 1 \mathrm{mM}$ EGTA and 1\% NP-40) and immunoprecipitated with anti-FLAG agarose-conjugated beads. The precipitates were extensively washed and analyzed by western blotting using an HRP-conjugated anti-HA antibody (Roche, Basel, Switzerland) or anti-ubiquitin, Lys48-Specific (Millipore, 05-1307).

SNIPER-mediated interaction of TACC3 and APC/C ${ }^{\mathrm{CDH} 1}$. Cells were co-transfected for $40 \mathrm{~h}$ with the expression vectors of Flag-TACC3 and Myc$\mathrm{CDH} 1$ and treated for $3 \mathrm{~h}$ with MG132 in the presence or absence of SNIPER (TACC3)-1. Cells were lysed with IP lysis buffer (10 mM Hepes at pH 7.4, $142.5 \mathrm{mM}$ $\mathrm{KCl}, 5 \mathrm{mM} \mathrm{MgCl}, 1 \mathrm{mM}$ EGTA and $0.1 \%$ Triton X-100) containing a protease inhibitor cocktail, rotated for $15 \mathrm{~min}$ at $4{ }^{\circ} \mathrm{C}$ and centrifuged at 15000 r.p.m. for $10 \mathrm{~min}$ at $4^{\circ} \mathrm{C}$ to obtain the supernatants. The lysates, which had been precleared with naked protein G-sepharose, were immunoprecipitated with anti-FLAG agaroseconjugated beads for $2 \mathrm{~h}$ at $4^{\circ} \mathrm{C}$. The precipitates were washed with IP lysis buffer four times and eluted by mild vortexing with IP lysis buffer containing the compounds for $15 \mathrm{~min}$ at room temperature. After centrifugation at 15000 r.p.m. for $1 \mathrm{~min}$, the eluted fractions (the supernatants) were obtained and analyzed by western blotting.

Thermal shift assay. Thermal shift assay was performed as previously described. ${ }^{32}$ Cells were harvested and washed with PBS. The cells were suspended in kinase buffer ( $25 \mathrm{mM}$ Tris(hydroxymethyl)-aminomethane hydrochloride (Tris- $\mathrm{HCl}$, $\mathrm{pH}$ 7.5), $5 \mathrm{mM}$ beta-glycerophosphate, $2 \mathrm{mM}$ dithiothreitol, $0.1 \mathrm{mM}$ sodium vanadium oxide, $10 \mathrm{mM}$ magnesium chloride) (Cell Signaling Technology) supplemented with protease inhibitor cocktail. The cell suspensions were freezethawed three times using liquid nitrogen and centrifuged at 15000 r.p.m. for $10 \mathrm{~min}$ at $4{ }^{\circ} \mathrm{C}$ to obtain the supernatants (lysate). The cell lysates were divided into four aliquots, with each aliquot being treated with each compound or DMSO (control). After 10-30 min incubation at room temperature, the respective lysates were divided into smaller $(50 \mu l)$ aliquots and heated individually at graded temperatures for $3 \mathrm{~min}$ (PCR thermal cycler, Applied Biosystems/Life Technologies, Carlsbad, CA, USA) followed by cooling for $3 \mathrm{~min}$ at room temperature. The heated lysates were centrifuged at 15000 r.p.m. for $10 \mathrm{~min}$ at $4{ }^{\circ} \mathrm{C}$ in order to separate the soluble fractions from precipitates. The supernatants were transferred to new microtubes and analyzed by SDS-PAGE followed by western blotting.
Cell viability assay. Cell viability was determined using water-soluble tetrazolium WST-8 (4-[3-(2-methoxy-4-nitrophenyl)-2-(4-nitrophenyl)-2H-5-tetrazolio]-1,3-benzene disulfonate) for the spectrophotometric assay according to the manufacturer's instructions (Dojindo, Tokyo, Japan). Cells were seeded at a concentration of $5 \times 10^{3}$ cells per well in a 96-well culture plate. After $24 \mathrm{~h}$, cells were treated with the indicated compounds for $48 \mathrm{~h}$. The WST- 8 reagent was added, and the cells were incubated for $0.5 \mathrm{~h}$ at $37^{\circ} \mathrm{C}$ in a humidified atmosphere of $5 \%$ $\mathrm{CO}_{2}$. The absorbance at $450 \mathrm{~nm}$ of the medium was measured using an EnVision Multilabel Plate Reader (PerkinElmer, Waltham, MA, USA).

Measurement of apoptosis by flow cytometer. Apoptosis was analyzed with an Annexin V-FITC Apoptosis Detection Kit (BioVision, Milpitas, CA, USA). After treatment, cells were gently trypsinized and washed with serumcontaining medium. Cells were collected by centrifugation, and additionally washed with PBS, and resuspended in Binding Buffer. The cells were stained with annexin V-FITC and PI at room temperature for $5 \mathrm{~min}$ in the dark, according to the manufacturer's instructions, and analyzed on a FACScan flow cytometer (Becton Dickinson, Braintree, MA, USA).

Cell cycle analysis. After treatment, cells were gently trypsinized and washed with serum-containing medium. Cells were collected by centrifugation, and additionally washed with PBS, and fixed in $70 \%$ ice-cold ethanol for $1 \mathrm{~h}$ on ice. The cells were then washed, treated with $1 \mathrm{mg} / \mathrm{ml}$ RNase $A$ for $1 \mathrm{~h}$ at $37^{\circ} \mathrm{C}$ and stained in PI solution $(50 \mu \mathrm{g} / \mathrm{ml}$ in $0.1 \%$ sodium citrate, $0.1 \% \mathrm{NP}-40)$. The stained cells were analyzed on a FACScan flow cytometer (Becton Dickinson).

\section{Conflict of Interest}

K Nagai and N Cho are employees of Takeda Pharmaceutical Co., Ltd. (Osaka, Japan). M Naito received a research fund from Takeda Pharmaceutical Co., Ltd. The other authors declare no conflict of interest.

Acknowledgements. We thank Dr. N Miyamoto, Dr. M Ito and Dr. Y Morita for helpful discussions, and Dr. R Yao for information on TACC3. This study was supported by Grants-in Aid for Scientific Research from the Japan Society for the Promotion of Science (to MN and NO) and Research Fund from the Japan Health Sciences Foundation (to MN). Pacific Edit reviewed the manuscript prior to submission.

1. Sudakin V, Yen TJ. Targeting mitosis for anti-cancer therapy. BioDrugs 2007; 21: 225-233.

2. Lens SM, Voest EE, Medema RH. Shared and separate functions of polo-like kinases and aurora kinases in cancer. Nat Rev Cancer 2010; 10: 825-841.

3. Jackson JR, Patrick DR, Dar MM, Huang PS. Targeted anti-mitotic therapies: can we improve on tubulin agents? Nat Rev Cancer 2007; 7: 107-117.

4. Hood FE, Royle SJ. Pulling it together: the mitotic function of TACC3. Bioarchitecture 2011; 1: 105-109.

5. Gergely F, Karlsson C, Still I, Cowell J, Kilmartin J, Raff JW. The TACC domain identifies a family of centrosomal proteins that can interact with microtubules. Proc Natl Acad Sci USA 2000; 97: 14352-14357.

6. LeRoy PJ, Hunter JJ, Hoar KM, Burke KE, Shinde V, Ruan J et al. Localization of human TACC3 to mitotic spindles is mediated by phosphorylation on Ser558 by Aurora A: a novel pharmacodynamic method for measuring Aurora A activity. Cancer Res 2007; 67: 5362-5370.

7. Lin $\mathrm{CH}, \mathrm{Hu} \mathrm{CK}$, Shih HM. Clathrin heavy chain mediates TACC3 targeting to mitotic spindles to ensure spindle stability. J Cell Biol 2010; 189: 1097-1105.

8. Booth DG, Hood FE, Prior IA, Royle SJ. A TACC3/ch-TOG/clathrin complex stabilises kinetochore fibres by inter-microtubule bridging. EMBO J 2011; 30: 906-919,

9. Fu W, Tao W, Zheng P, Fu J, Bian M, Jiang Q et al. Clathrin recruits phosphorylated TACC3 to spindle poles for bipolar spindle assembly and chromosome alignment. J Cell Sci 2010; 123(Pt 21): 3645-3651.

10. Lioutas A, Vernos I. Aurora A kinase and its substrate TACC 3 are required for central spindle assembly. EMBO Rep 2013; 14: 829-836.

11. Hood FE, Williams SJ, Burgess SG, Richards MW, Roth D, Straube A et al. Coordination of adjacent domains mediates TACC3-ch-TOG-clathrin assembly and mitotic spindle binding. J Cell Biol 2013; 202: 463-478.

12. Ma XJ, Salunga R, Tuggle JT, Gaudet J, Enright E, McQuary P et al. Gene expression profiles of human breast cancer progression. Proc Natl Acad Sci USA 2003; 100: 5974-5979.

13. Jacquemier J, Ginestier C, Rougemont J, Bardou VJ, Charafe-Jauffret E, Geneix J et al. Protein expression profiling identifies subclasses of breast cancer and predicts prognosis. Cancer Res 2005; 65: 767-779. 
14. Lauffart B, Vaughan MM, Eddy R, Chervinsky D, DiCioccio RA, Black JD et al. Aberrations of TACC1 and TACC3 are associated with ovarian cancer. BMC Womens Health 2005; 5 : 8.

15. Kimura M, Yoshioka T, Saio M, Banno Y, Nagaoka H, Okano Y. Mitotic catastrophe and cell death induced by depletion of centrosomal proteins. Cell Death Dis 2013; 4: e603.

16. Piekorz RP, Hoffmeyer A, Duntsch CD, McKay C, Nakajima H, Sexl V et al. The centrosomal protein TACC3 is essential for hematopoietic stem cell function and genetically interfaces with p53-regulated apoptosis. EMBO J 2002; 21: 653-664.

17. Schmidt S, Schneider L, Essmann F, Cirstea IC, Kuck F, Kletke A et al. The centrosomal protein TACC3 controls paclitaxel sensitivity by modulating a premature senescence program. Oncogene 2010; 29: 6184-6192.

18. Schneider L, Essmann F, Kletke A, Rio $P$, Hanenberg $H$, Schulze-Osthoff $K$ et al. TACC3 depletion sensitizes to paclitaxel-induced cell death and overrides p21WAF-mediated cell cycle arrest. Oncogene 2008; 27: 116-125.

19. Schneider L, Essmann F, Kletke A, Rio P, Hanenberg H, Wetzel W et al. The transforming acidic coiled coil 3 protein is essential for spindle-dependent chromosome alignment and mitotic survival. J Biol Chem 2007; 282: 29273-29283.

20. Yao R, Natsume $Y$, Noda T. TACC3 is required for the proper mitosis of sclerotome mesenchymal cells during formation of the axial skeleton. Cancer Sci 2007; 98: 555-562.

21. Yao R, Natsume Y, Saiki Y, Shioya H, Takeuchi K, Yamori T et al. Disruption of Tacc3 function leads to in vivo tumor regression. Oncogene 2012; 31: 135-148.

22. Okuhira K, Ohoka N, Sai K, Nishimaki-Mogami T, Itoh $Y$, Ishikawa M et al. Specific degradation of CRABP-II via cIAP1-mediated ubiquitylation induced by hybrid molecules that crosslink cIAP1 and the target protein. FEBS Lett 2011; 585: 1147-1152.

23. Itoh $Y$, Ishikawa M, Naito M, Hashimoto Y. Protein knockdown using methyl bestatin-ligand hybrid molecules: design and synthesis of inducers of ubiquitination-mediated degradation of cellular retinoic acid-binding proteins. J Am Chem Soc 2010; 132: 5820-5826.

24. Itoh $Y$, Kitaguchi R, Ishikawa M, Naito M, Hashimoto $Y$. Design, synthesis and biological evaluation of nuclear receptor-degradation inducers. Bioorg Med Chem 2011; 19: 6768-6778.

25. Itoh Y, Ishikawa M, Kitaguchi R, Sato S, Naito M, Hashimoto Y. Development of target proteinselective degradation inducer for protein knockdown. Bioorg Med Chem 2011; 19: 3229-3241.

26. Itoh $Y$, Ishikawa M, Kitaguchi R, Okuhira K, Naito M, Hashimoto Y. Double protein knockdown of cIAP1 and CRABP-II using a hybrid molecule consisting of ATRA and IAPS antagonist. Bioorg Med Chem Lett 2012; 22: 4453-4457.

27. Demizu Y, Okuhira K, Motoi H, Ohno A, Shoda T, Fukuhara K et al. Design and synthesis of estrogen receptor degradation inducer based on a protein knockdown strategy. Bioorg Med Chem Lett 2012; 22: 1793-1796.

28. Okuhira K, Demizu Y, Hattori T, Ohoka N, Shibata N, Nishimaki-Mogami T et al. Development of hybrid small molecules that induce degradation of estrogen receptor-alpha and necrotic cell death in breast cancer cells. Cancer Sci 2013; 24: 87-89.

29. Sekine K, Takubo K, Kikuchi R, Nishimoto M, Kitagawa M, Abe F et al. Small molecules destabilize cIAP1 by activating auto-ubiquitylation. J Biol Chem 2008; 283: 8961-8968.

30. Jeng JC, Lin YM, Lin CH, Shih HM. Cdh1 controls the stability of TACC3. Cell Cycle 2009; 8 : 3529-3536.

31. Peters JM. The anaphase promoting complex/cyclosome: a machine designed to destroy. Nat Rev Mol Cell Biol 2006; 7: 644-656.
32. Martinez Molina D, Jafari R, Ignatushchenko M, Seki T, Larsson EA, Dan C et al. Monitoring drug target engagement in cells and tissues using the cellular thermal shift assay. Science 2013; 341: 84-87.

33. Malumbres M, Barbacid M. Cell cycle, CDKs and cancer: a changing paradigm. Nat Rev Cancer 2009; 9(3): 153-166.

34. Ha GH, Kim JL, Breuer EK. Transforming acidic coiled-coil proteins (TACCs) in human cancer. Cancer Lett 2013; 336: 24-33.

35. Cappell KM, Sinnott R, Taus P, Maxfield K, Scarbrough M, Whitehurst AW. Multiple cancer testis antigens function to support tumor cell mitotic fidelity. Mol Cell Biol 2012; 32: 4131-4140.

36. Guo G, Sun X, Chen C, Wu S, Huang P, Li Z et al. Whole-genome and whole-exome sequencing of bladder cancer identifies frequent alterations in genes involved in sister chromatid cohesion and segregation. Nat Genet 2013; 45: 1459-1463.

37. Kiemeney LA, Sulem P, Besenbacher S, Vermeulen SH, Sigurdsson A, Thorleifsson G et al. A sequence variant at $4 \mathrm{p} 16.3$ confers susceptibility to urinary bladder cancer. Nat Genet 2010; 42: 415-419.

38. Parker BC, Annala MJ, Cogdell DE, Granberg KJ, Sun Y, Ji P et al. The tumorigenic FGFR3TACC3 gene fusion escapes miR-99a regulation in glioblastoma. J Clin Invest 2013; 123: 855-865.

39. Shinmura $\mathrm{K}$, Kato $\mathrm{H}$, Matsuura $\mathrm{S}$, Inoue $\mathrm{Y}$, Igarashi $\mathrm{H}$, Nagura $\mathrm{K}$ et al. A novel somatic FGFR3 mutation in primary lung cancer. Oncol Rep 2014; 31: 1219-1224.

40. Singh D, Chan JM, Zoppoli P, Niola F, Sullivan R, Castano A et al. Transforming fusions of FGFR and TACC genes in human glioblastoma. Science 2012; 337: 1231-1235.

41. Williams SV, Hurst CD, Knowles MA. Oncogenic FGFR3 gene fusions in bladder cancer. Hum Mol Genet 2013; 22: 795-803.

42. Yao R, Kondoh $\mathrm{Y}$, Natsume $\mathrm{Y}$, Yamanaka $\mathrm{H}$, Inoue $\mathrm{M}$, Toki $\mathrm{H}$ et al. A small compound targeting TACC3 revealed its different spatiotemporal contributions for spindle assembly in cancer cells. Oncogene 2013; 33: 4242-4252.

43. Wurdak $\mathrm{H}$, Zhu S, Min KH, Aimone L, Lairson LL, Watson $\mathrm{J}$ et al. A small molecule accelerates neuronal differentiation in the adult rat. Proc Natl Acad Sci USA 2010; 107 16542-16547.

44. Ohoka N, Sakai S, Onozaki K, Nakanishi M, Hayashi H. Anaphase-promoting complex/ cyclosome-cdh1 mediates the ubiquitination and degradation of TRB3. Biochem Biophys Res Commun 2010; 392: 289-294.

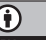

Cell Death and Disease is an open-access journal published by Nature Publishing Group. This work is licensed under a Creative Commons Attribution 4.0 International Licence. The images or other third party material in this article are included in the article's Creative Commons licence, unless indicated otherwise in the credit line; if the material is not included under the Creative Commons licence, users will need to obtain permission from the licence holder to reproduce the material. To view a copy of this licence, visit http://creativecommons.org/licenses/by/4.0

Supplementary Information accompanies this paper on Cell Death and Disease website (http://www.nature.com/cddis) 